\title{
Control design variable speed drive three-phase induction motor based cascaded H-Bridge seven level
}

\author{
Muhamad Otong ${ }^{1, *}$, Ceri Ahendyarti ${ }^{2}$ \\ ${ }^{1}$ Universitas Sultan Ageng Tirtayasa, Power Systems Department, 42435 Banten, Indonesia \\ ${ }^{2}$ Universitas Sultan Ageng Tirtayasa, Instrumentation Department, 42435 Banten, Indonesia
}

\begin{abstract}
The design variable speed drive induction motor is based on the power supply system of cascaded H-bridge seven level inverter. The variable speed regulation of the induction motor is performed by controlling the variable magnitude and output voltage frequency of the $\mathrm{CHB}$ circuit. The output voltage of the CHB circuit is generated by synthesizing the reference voltage signal derived from the field oriented control algorithm model of the induction motor. Testing and circuit operation mode using switching phase-switch technique on variable speed drive system of induction motor is done to know system performance in transient and steady-state by using computer software. The response of the simulation shows the conformity of the proposed concept. From this research is expected to improve the quality and capacity of output power in modular way so that it can be applied to the electric drive in general.
\end{abstract}

\section{Introduction}

Controlling the induction motor speed variable requires a controlled DC to AC voltage converter circuit or also called the "inverter" [1] - [3]. The form of cascaded H-bridge (CHB) multilevel inverter is a power electronics converter circuit that is very popular and suitable for applications that require high power. The advantage of using the CHB multilevel inverter circuit topology is to reduce harmonic distortion, reduce electromagnetic interference, and can be manufactured in a modular form [3] - [5]. The expected goal in this paper is to design a controlled AC voltage source that can be used to supply and control the speed of the induction motor and design an induction motor variable speed control algorithm using the field oriented control (FOC) method.

\section{CHB Multilevel inverter circuit topology}

As the name implies, the CHB multilevel inverter circuit is formed by connecting the basic module block of the H-bridge inverter in series or multilevel to get a higher output voltage and also to reduce harmonic defects. Figure 1 is an example of a topology of a 5-

*Corresponding author: muhamadotonguntirta@yahoo.com 
level multilevel CHB series inverter consisting of 2 block modules of the H-bridge inverter circuit and supplied by an isolated DC voltage E. In figure 1, the multilevel inverter CHB circuit can produce 5- voltage level in each phase. When the switch $S_{11}, S_{21}, S_{12}$, and $S_{22}$ is on conduction, then the output voltage of the inverter for the H1 module and the $\mathrm{H} 2$ module is $v_{H 1}=v_{H 2}=E$, and the phase voltage phase output CHB multilevel inverter is $v_{A N}=v_{H 1}+v_{H 2}=2 E$. In the same way, when the switch $S_{31}, S_{41}, S_{32}$ and $S_{42}$ is on conduction, , then the output voltage of the inverter for the $\mathrm{H} 1$ module and the $\mathrm{H} 2$ module is $v_{A N}=v_{H 1}+v_{H 2}=-2 E$.

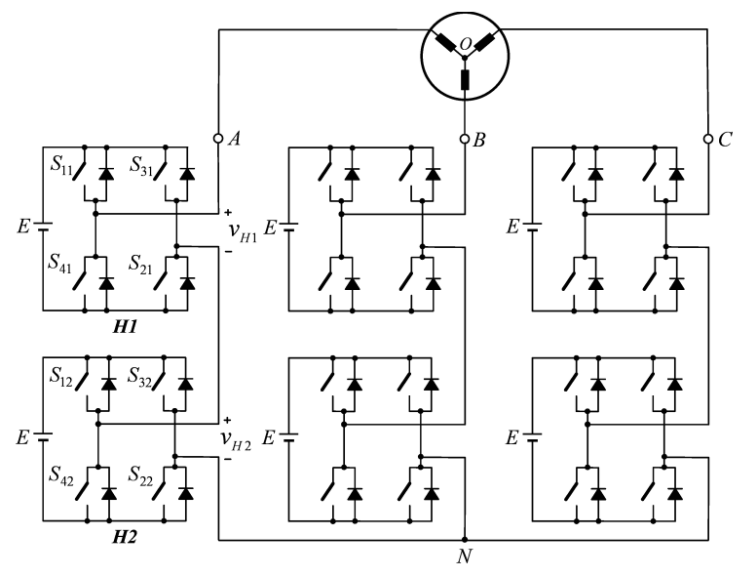

Fig. 1. CHB multilevel 5-level inverter circuit.

In general, the number of voltage levels generated by the multilevel inverter CHB circuit output can be formulated as follows: $m=2 H+1$

With $\mathrm{H}$ is the number of $\mathrm{H}$-bridge modules per phase, and $\mathrm{m}$ is the number of voltage levels generated by the multilevel inverter CHB circuit whose value is always in the form of an odd number

\section{CHB Multilevel inverter control using phase-shift SPWM}

The basic principle of the Phase-shifted SPWM (sinusoidal pulse width modulation) scheme in a CHB multilevel inverter circuit with m-level voltage can be developed using a unipolar modulation technique that requires a number of $(\mathrm{m}-1)$ carrier triangle waves with the same magnitude and frequency but having the difference-phase angle between 2 pieces of carrier wave adjacent triangle is shifted (phase-shifted) by : $\phi_{c r}=\frac{360^{\circ}}{(\mathrm{m}-1)}$.

The signal to be modulated is usually a three-phase sinusoidal wave that can be adjusted either magnitude or frequency or both. The gate signal generated is obtained by comparing the signal to be modulated with the triangular carrier signal.

Figure 2 is an example of a voltage output waveform in a 7-level multilevel CHB circuit generated by using the principle of the Phase-shifted SPWM scheme which has 6 carrier waves and a different phase of 600 (only phase-A is shown). 


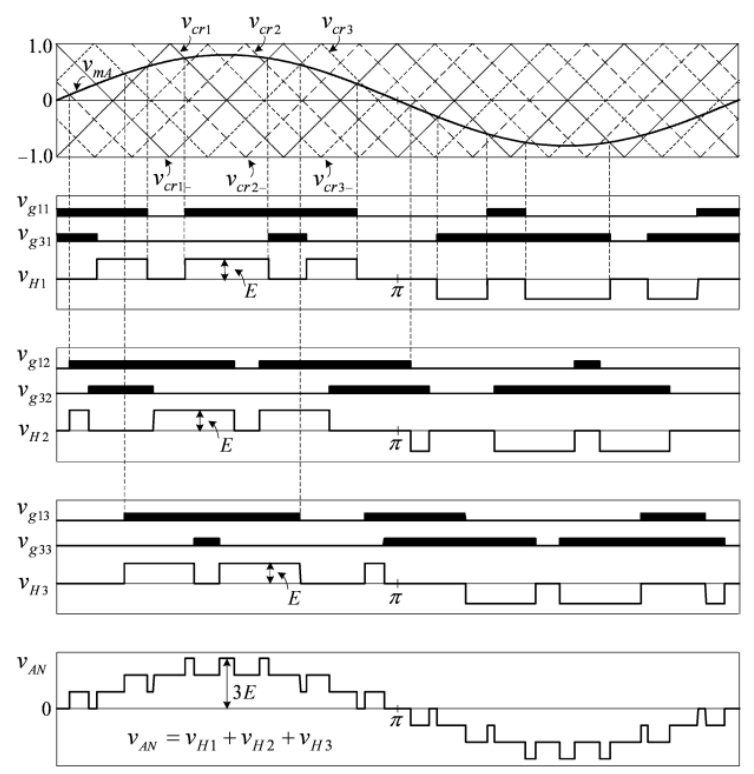

Fig. 2. Seven level multilevel CHB voltage output form uses Phase-shifted SPWM.

\section{Dynamic modelling of induction motor}

Making an induction motor modelling is the first step that must be done in designing a control system. Equation (1) through equation (6) is a dynamic model of an induction motor given in the form of a differential equation using the transformation of the coordinate axis dq (Park Transformation) which is placed parallel to the direction of the rotor magnetic field flux (rotor flux field oriented) [1], [4].

$$
\begin{gathered}
T_{\theta}=\frac{3}{2} Z_{p} \frac{L_{h}}{L_{r}} \Psi_{r d}(t) i_{s q}(t) \\
\Psi_{r d}^{\prime}(t)+\tau_{r} \frac{d \Psi_{r d}^{\prime}(t)}{d t}=L_{h} i_{s d}(t) \\
\omega_{s}(t)=\omega_{\theta}(t)+\frac{L_{h} i_{s q}(t)}{\tau_{r} \Psi_{r d}(t)} \\
\frac{d \omega_{m}(t)}{d t}=-\frac{f_{d}}{J_{m}} \omega_{m}(t)+\frac{3}{2} \frac{z_{p} L_{h}}{L_{r} J_{m}} \Psi_{r d}(t) i_{s q}(t)-\frac{T_{L}}{J_{m}} \\
i_{s q}(t)+\tau_{\sigma}^{\prime} \frac{d i_{s q}(t)}{d t}=-\omega_{s}(t) \tau_{\sigma}^{\prime} i_{s d}(t)-\frac{k_{r}}{r_{\sigma}} \Psi_{r d}(t)+\frac{1}{r_{\sigma}} u_{s q}(t) \\
i_{s d}(t)+\tau_{\sigma}^{\prime} \frac{d i_{s d}(t)}{d t}=\omega_{s}(t) \tau_{\sigma}^{\prime} i_{s q}(t)+\frac{k_{r}}{r_{\sigma} \tau_{r}} \Psi_{r d}(t)+\frac{1}{r_{\sigma}} u_{s d}(t)
\end{gathered}
$$

\section{Design induction motor speed control systems}

From the point of view of the control system design, it can be seen in the dynamic equation (5) and (6) that the variables that are manipulated to formulate the problem of the induction motor control system are determining the stator voltage signal $u_{s d}(t)$ and 
$u_{s q}(t)$, in this case it is a reference voltage signal to the input signal to the PWM inverter. Therefore, to determine and manipulate the stator voltage signal. Therefore, to determine and manipulate the stator voltage signal $u_{s d}(t)$ and $u_{s q}(t)$ then we need a current controller which functions to regulate the amount of stator current $i_{s d}(t)$ dan $i_{s q}(t)$ in accordance with the motor operating mode as shown in Figure 3.

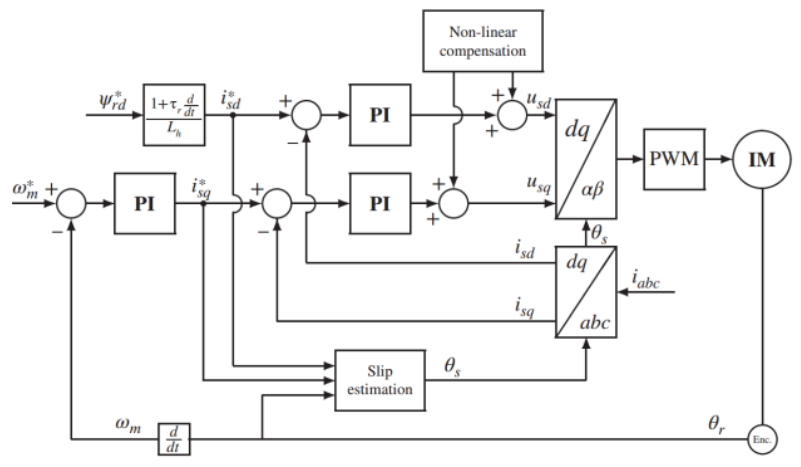

Fig. 3. Block diagram of the induction motor speed control system

Because the purpose of the induction motor control system design that is desirable is to regulate its speed, it can be seen also in equations (4) and (6) that the goal will be achieved by manipulating and controlling the current $i_{s q}(t)$ and maintain the magnitude of the rotor flux $\Psi_{r d}^{\prime}(t)$ constantly at nominal value.

\section{Simulation and analysis}

Table 1 are some of the system parameter data needed for simulation on an induction motor variable speed drive (VSD) system.

Figure 5 is the response of the actual output speed of the induction motor rotor. Seen in Figure 5 when $t=1$ second the speed is inputted with the step $150 \mathrm{rad} / \mathrm{second}$ function, and the system responds with a speed that continues to rise linearly from the starting point, then the speed reaches a steady-state response of $150 \mathrm{rad} /$ seconds at $\mathrm{t}=1.63$ seconds.

Table 1. Data of 3 phase induction motor and CHB seven level inverter

\begin{tabular}{|c|c|c|c|}
\hline Power (Hp) & $\mathrm{HP}=50$ & Cascaded H-bridge & $\mathrm{n}=3$ \\
\hline Voltage (volt) & $\mathrm{Vll}=460$ & Level inverter $\mathrm{m}$ & $2 . n+1=7$ level \\
\hline Frequency (Herz) & $f=60 \mathrm{~Hz}$ & Switch Type & IGBT and Diode \\
\hline Pole & $z \_p=2$ & Switching frequency & $\mathrm{f}_{\mathrm{c}}=12 \mathrm{KHz}$ \\
\hline Inertia $\left(\mathrm{Kg} \cdot \mathrm{m}^{2}\right)$ & $\mathrm{J}=0,4$ & DC Bus H- bridge & $\mathrm{E}=125,2$ Volt \\
\hline Friction (N.m.s) & $\mathrm{F}=0,02187$ & & \\
\hline Stator resistance Ohm & $\mathrm{r}_{-} \mathrm{s}=0,09961$ & & \\
\hline Stator inductance $(\mathrm{H})$ & $1 \_s=0,031257$ & & \\
\hline Rotor resistance Ohm & $\mathrm{r}_{-} \mathrm{r}=0,05837$ & & \\
\hline Rotor inductance Henry & $1 \_r=0,031257$ & & \\
\hline Mutual induktansi Henry & $1 \mathrm{~h}=0,03039$ & & \\
\hline
\end{tabular}




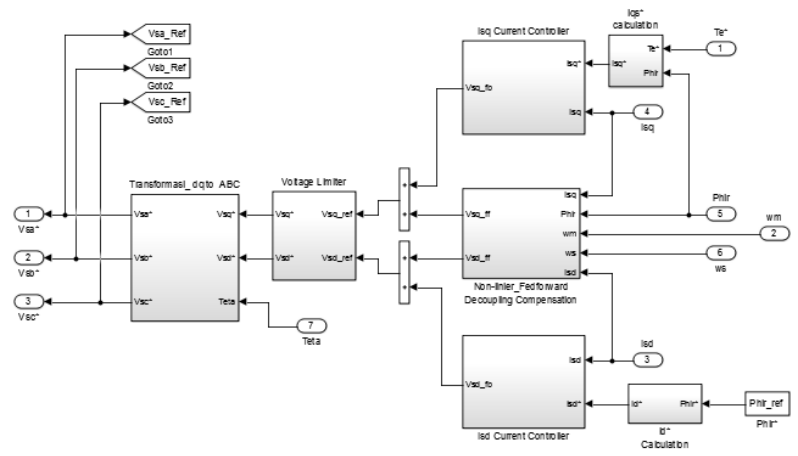

Fig. 4. Block variable speed drive induction motor system
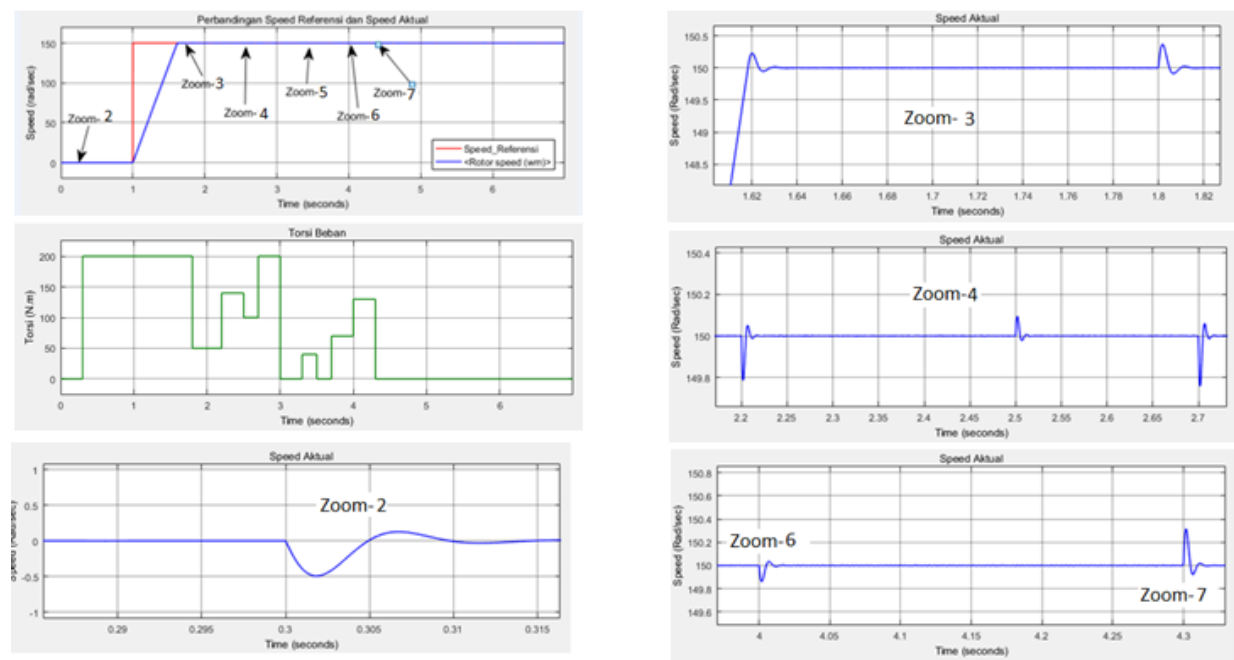

Fig. 5. Speed responds with load torque disturbance.
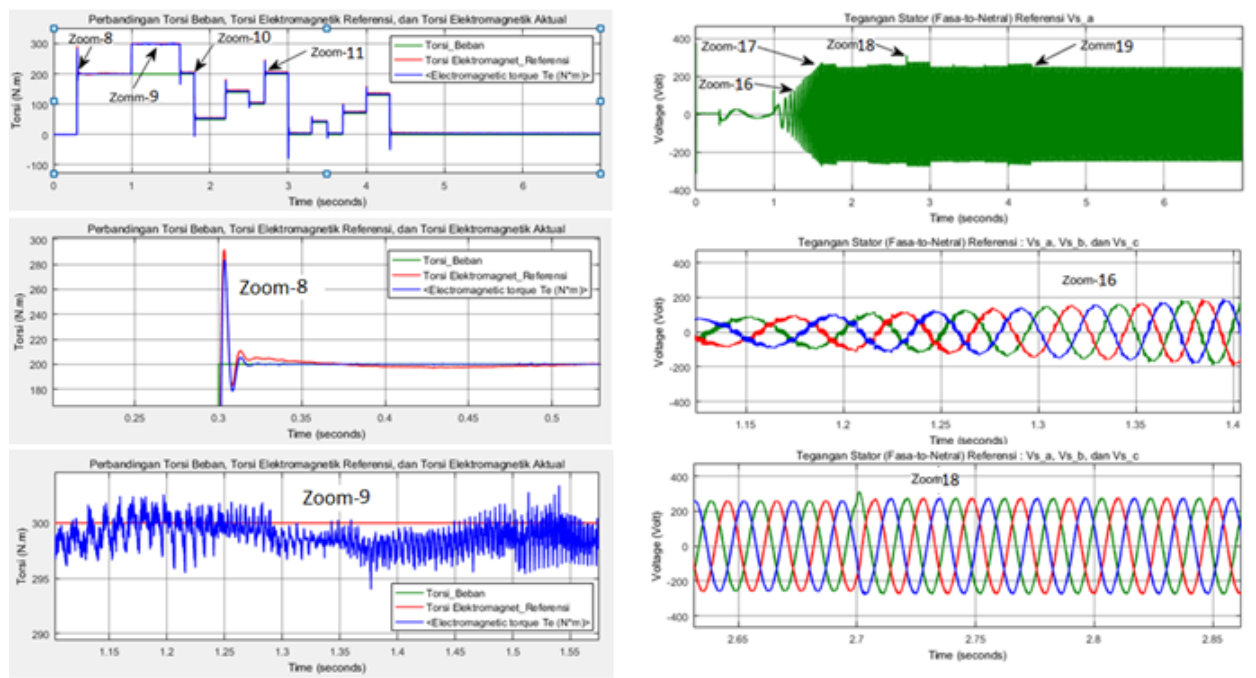

Fig. 6. Respond electromagnetic torque, and synthesizing the reference stator voltage signal. 

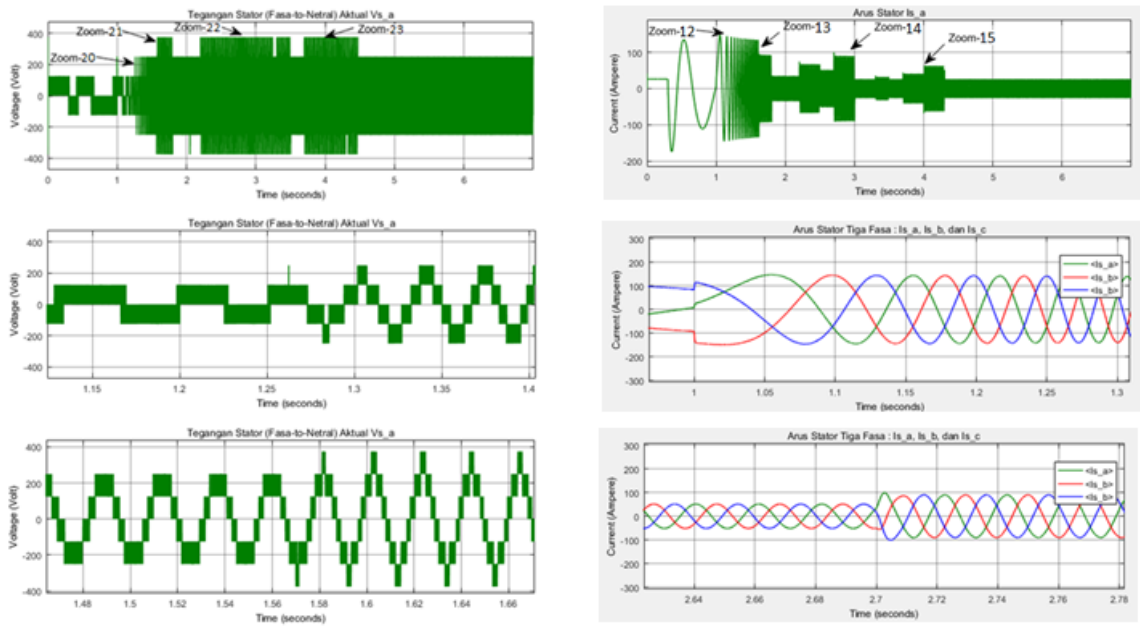

Fig. 7. Output voltage from $\mathrm{CHB}$ seven level inverter, and respond stator current

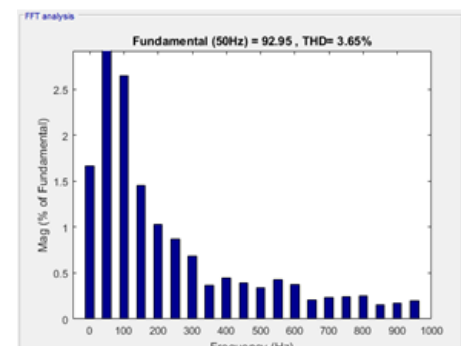

(a)

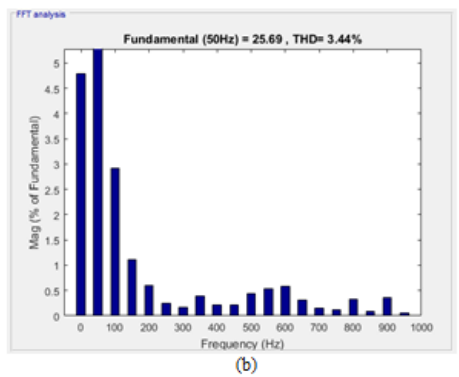

(b)

Fig. 7. (a) Harmonic spectrum of stator current at $1.7 \mathrm{sec}$, speed $150 \mathrm{rad} / \mathrm{sec}$, load torque 200 N.m.

(b) Harmonic spectrum of stator current at $6.0 \mathrm{sec}$, speed $150 \mathrm{rad} / \mathrm{sec}$, no load torque.

\section{Conclusion}

From the results simulation and analysis of the discussion in Section 6, it can be concluded that the design using the CHB multilevel inverter circuit topology has fulfilled the requirements to be used as a controlled voltage sources in supplying induction motor loads. This is indicated by the occurrence of a process of improving the quality of power with the form of a stator current that is almost sinusoidal by producing total harmonic distortion (THD) of $3.65 \%$. The simulation results also show that, the FOC induction motor algorithm can control and track the rotational speed of the induction motor rotor according to the desired reference speed signal by producing a speed overshoot of $0.17 \%$ in 0.62 seconds and the system reaches a steady state-state within 0.02 seconds after transient occurs.

\section{References}

1. I.G. Christopher Raj, P. Renuga, M. Arul Prasanna, IJEPE, 3, (2010)

2. J. Gholinezhad, R. Noroozian, JEET, 8, 304-315, (2013)

3. S. Vazquez, J. I. Leon, L. G. Franquelo, J. J. Padilla, J. M. Carrasco, IEEE, 56, (2009)

4. A. Mishra, P. Choudhary, IJETAE, 2, (2012) 